\title{
3D-Printed Scaffolds and Biomaterials: Review of Alveolar Bone Augmentation and Periodontal Regeneration Applications
}

\author{
Farah Asa'ad, ${ }^{1}$ Giorgio Pagni, ${ }^{1}$ Sophia P. Pilipchuk, ${ }^{2,3}$ Aldo Bruno Giannì, \\ William V. Giannobile, ${ }^{2,3}$ and Giulio Rasperini ${ }^{1}$ \\ ${ }^{1}$ Department of Biomedical, Surgical and Dental Sciences, Foundation IRCCS Ca' Granda Polyclinic, University of Milan, Milan, Italy \\ ${ }^{2}$ Department of Periodontics and Oral Medicine, School of Dentistry, University of Michigan, Ann Arbor, MI, USA \\ ${ }^{3}$ Department of Biomedical Engineering, College of Engineering, University of Michigan, Ann Arbor, MI, USA
}

Correspondence should be addressed to Farah Asa’ad; farahasaad83@gmail.com

Received 12 February 2016; Revised 17 April 2016; Accepted 10 May 2016

Academic Editor: Saso Ivanovski

Copyright (C) 2016 Farah Asa'ad et al. This is an open access article distributed under the Creative Commons Attribution License, which permits unrestricted use, distribution, and reproduction in any medium, provided the original work is properly cited.

\begin{abstract}
To ensure a successful dental implant therapy, the presence of adequate vertical and horizontal alveolar bone is fundamental. However, an insufficient amount of alveolar ridge in both dimensions is often encountered in dental practice due to the consequences of oral diseases and tooth loss. Although postextraction socket preservation has been adopted to lessen the need for such invasive approaches, it utilizes bone grafting materials, which have limitations that could negatively affect the quality of bone formation. To overcome the drawbacks of routinely employed grafting materials, bone graft substitutes such as 3D scaffolds have been recently investigated in the dental field. In this review, we highlight different biomaterials suitable for 3D scaffold fabrication, with a focus on "3D-printed" ones as bone graft substitutes that might be convenient for various applications related to implant therapy. We also briefly discuss their possible adoption for periodontal regeneration.
\end{abstract}

\section{Introduction}

Placement of endosseous implants has revolutionized modern dentistry, with a constantly increasing number of patients seeking replacement of lost teeth with this modality of treatment.

Since the overall success of dental implant therapy depends on the presence of adequate bone volume at implant sites [1], sufficient vertical and horizontal amounts of alveolar ridge prior to dental implant placement are essential especially in the anterior maxilla, which is a highly demanding aesthetic region.

Bone augmentation can be carried out using different techniques: bone blocks or guided bone regeneration (GBR) is mainly applied for horizontal grafting [2]. Vertical bone augmentation employs more challenging and techniquesensitive methods (vertical GBR, onlay grafting, inlay grafting, and distraction osteogenesis $[3,4]$ ) and is frequently associated with high complication rates such as soft tissue dehiscence and subsequent exposure of bone grafts to the oral cavity [5].
In an attempt to overcome the obstacles related to vertical bone augmentation, short dental implants have been suggested as an alternative in the atrophic areas [6]. Despite being an acceptable option in the posterior areas of both jaws, bone grafting is still obligatory in anterior regions with severe bone resorption to achieve final satisfactory aesthetic results.

Bone grafts serve as filling materials with alternating properties of space maintenance, blood clot stabilization, and scaffolding [7], by providing a temporary template to support migration of cells from the periphery of the grafted area [8]. Bone grafting materials are divided into autografts, allografts, xenografts, and alloplasts, each with its own set of advantages and disadvantages [9]. As a result, researchers are constantly working on exploring new bone graft substitutes with more predictable regenerative outcomes and minimal complications. To this end, tissue engineering has become more commonly used for oral bone grafting procedures.

The specific field of tissue engineering that mainly focuses on enhancing bone regeneration and repair by creating substitutes to traditional bone grafting materials is referred to as bone tissue engineering (BTE) [10] which started about 
three decades ago and has been witnessing a tremendous growth ever since [11]. This could be ascribed to the high regenerative potential of bone in comparison to other tissues in the body, thus serving as a paradigm for general principles in tissue engineering [12]. A classic BTE paradigm includes the following three key components: biomaterials to provide a scaffold for new tissue growth, cells, and signaling molecules $[11,13]$.

Within this model, scaffolds can be either acellular or cellular upon implantation. In the former, the overall architecture and geometry promote the recruitment of local stem cell and or/osteoprogenitor cells [14], which could be possible with "smart" cues and attachment motifs within the scaffold architecture. On the other hand, the latter strategy involves implantation of a scaffold combined with stem cell and or/osteoprogenitor cells [14], which can be incorporated by two methods: (i) cell seeding into a "prefabricated" scaffold, a commonly applied tissue engineering strategy, and (ii) cell encapsulation during scaffold fabrication made of hydrogel polymer matrix [15], based on the immobilisation of cells within a semipermeable membrane. This technique protects cells from the immune system [16] and permits uniform cell distribution within the construct [17].

In this narrative review, based on orthopaedic and dental studies available on PubMed, MEDLINE, and Google Scholar, we focus on the first key component of the tissue engineering paradigm for applications in alveolar bone and periodontal tissue regeneration, since scaffolds are considered the key players in successful tissue formation [14]. Biomolecules and cellular elements of the paradigm for this specific application are discussed elsewhere [18].

\section{Properties of 3D Scaffolds for Applications in Alveolar Bone and Periodontal Tissue Regeneration}

Although conventional bone grafting materials serve the role of a supporting matrix, they have several disadvantages: allografts, xenografts, and alloplasts are brittle, poorly processable into porous forms, and are unable to generate structures tailored to the specific needs of patients. Likewise, they are unable to maintain the desired generated tissue volume under mechanical forces, hindering their ability to provide a proper template for effective cell interaction [8]. Although autografts may have the ability to withstand mechanical forces, they are difficult to shape and conform to a bony defect [19], which is of a significant concern in the craniofacial region.

BTE has opened new doors for regeneration through the introduction of scaffolds which possess three-dimensional (3D) architecture that closely mimics native extracellular matrix (ECM). Such arrangements eventually enhance cell adhesion, proliferation, differentiation, and overall tissue regeneration [20]. As a matter of fact, scaffold properties are influenced by the used biomaterials and must be specific for the application while in harmony with the native environment to ensure that the defect area is replaced with a healthy, functional tissue matching the original one, without reparative scar formation [21].
In general, scaffolds must exhibit an adequate degree of hydrophilicity [22, 23], roughness [24], and specific surface topography; a topographic landscape on micro- and submicrometer scales must be developed to replicate the natural process of bone regeneration [25]. Nanotopography increases the overall surface area, surface-to-volume ratio, and surface roughness [26], which enhance the adhesion between osteoblasts and the underlying scaffold surfaces [27]. As for microscale features, they facilitate cell penetration, vascularization, and diffusion of nutrients [28] and offer better spatial organization for cell growth and ECM production [29]. Development of a multiscale scaffold has been emphasized in periodontal tissue regeneration [30].

Other important design characteristics are overall porosity, pore size, and interconnectivity. As human cancellous bone demonstrates a total porosity between $30 \%$ and $90 \%$, any construct enclosing voids within this range is considered suitable for bone regeneration [31]. However, extremely high porosity can jeopardize the overall mechanical stability of a scaffold by reducing its overall compressive strength [32]. For alveolar bone regeneration applications, an overall porosity of $70 \%$ has been applied in preclinical and clinical studies [33-35]. Regarding pore diameter, a range between $150 \mu \mathrm{m}$ and $500 \mu \mathrm{m}$ facilitates vascularization and penetration of new tissues [36] without compromising the mechanical strength of the scaffold [11] or cell infiltration into inner surface areas [37]. These consequential events are also dictated by the presence of an interconnected pore network, which is essential for cell growth into the interior of the scaffold to prevent core necrosis [38].

To achieve success in bone regeneration, the template should demonstrate mechanical strength close to native tissues to support target cells, the surrounding tissues, and newly formed ones, mainly in load-bearing areas, until full tissue formation is achieved $[39,40]$. In order to maintain this process, degradation rate of a scaffold should be in concordance with the remodeling processes of the target tissue [41]. For dentoalveolar reconstruction, degradation within 5-6 months is considered appropriate [42].

In addition, as implanted scaffolds should be biocompatible and bioactive, the utilized biomaterials should not elicit any inflammatory or cytotoxic reactions [43] and must evoke a specific biological response at the interface of the material, which results in the formation of a bond with the tissues [44].

Although the previously presented features constitute the basics in scaffold designing for bone regeneration, it must be noted that the design and balance between biomaterials and scaffolds are a complex and interdisciplinary matter. Furthermore, this aspect can become more complicated when alveolar bone regeneration is attempted along with cementum and periodontal ligament tissues. In this scenario, spatial organization is necessary by utilizing a multiphasic scaffold, which encloses variable architectural and chemical composition to closely capture the structural organization of native tissue and/or its cellular and biochemical composition [45]. Therefore, "compartmentalization" is essential for controlling the spatiotemporal events resulting in effective regeneration of the periodontal complex [45] which could prevent tooth ankylosis. This can be achieved by ensuring 


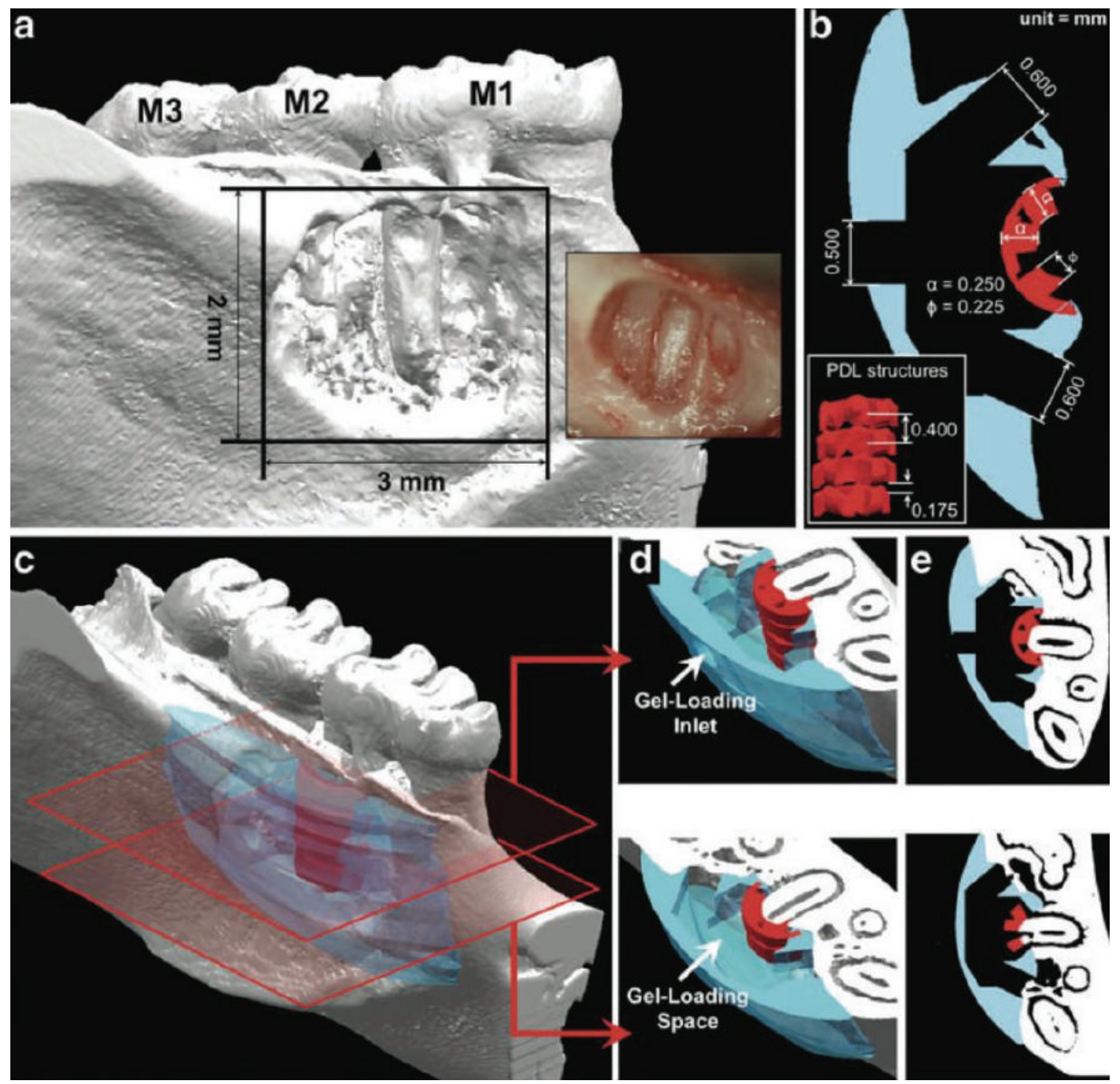

FIGURE 1: Multiphasic scaffold aimed at multiple tissue regeneration (periodontal ligament, cementum, and alveolar bone). Courtesy of Park et al., 2012 [46].

compartmentalized formation of bone and functionally oriented periodontal ligament fibers (PDL) that are integrated over time [45]. Figure 1 illustrates a multiphasic scaffold with channel-like "fiber-guiding architecture" of the PDL compartment displaying a thickness of $0.250 \mathrm{~mm}$ to mimic the width of an adult periodontal ligament space [46].

\section{Applied Biomaterials Used in the Fabrication of 3D Scaffolds for Alveolar Bone Regeneration}

As biomaterials strongly influence the overall properties of a scaffold, it is important to comprehend their individual characteristics to allow for appropriate selection in specific applications taking into consideration the notion that biomaterials differ in their cellular affinity [47], which influences adhesion, proliferation, and the overall regeneration outcome. As cell adhesion is mediated via integrins, such differences between biomaterials can be further explored. Below, we present biomaterials that can be mainly applied in alveolar bone regeneration and are compatible with new scaffold fabrication techniques.

3.1. Biodegradable Natural Polymers. Natural polymers, which include proteins and polysaccharides, are the first biomaterials to be recruited in different clinical 
applications because of their high biocompatibility, good cell recognition, enhanced cellular interactions in the surrounding environment [48], and hydrophilicity [49]. Due to these properties, they have been thoroughly investigated as hydrogels in the earliest work of cell encapsulation in tissue engineering, demonstrating successful results [50-54].

Collagen is one of the most widely expressed proteins in the human body, providing strength and structural stability to many tissues from skin to bone [55]. Being the major organic component of the ECM in native bone makes collagen an attractive biomaterial for BTE applications [56]. It is well documented that collagen matrices promote cell adhesion, proliferation, and osteogenic differentiation of bone marrow stromal cells, in vitro [55]. Similarly, the denatured form of collagen termed gelatin [57] enhances osteoblast adhesion, migration, and mineralization as it contains several biological and functional groups that promote such activities [58].

Regarding polysaccharides, chitosan is a popular biomaterial in bone tissue engineering due to its appealing characteristics; it displays antibacterial and antifungal activities, rapid blood clot formation, and analgesic properties [59], all of which render chitosan useful in wound healing acceleration that would minimize the risk of scaffold contamination and postoperative infections, thus preventing eventual exposure and failure of the scaffold.

For the same applications, alginate is another commonly investigated polysaccharide. It is highly processable into different scaffold types, which encourages its employment in BTE and regenerative medicine [60], and has been the most studied biomaterial for encapsulation of living cells [16]. Interestingly, alginate and chitosan do not exist within the human body, but they display structural similarities to glycosaminoglycans (GAGs) found in the ECM of human tissues such as bone [61], making them attractive candidates for applications in tissue regeneration.

Despite their good biological properties, the previously mentioned natural polymers lack bioactivity [62], which is the key factor in promoting hard tissue formation. They also share weak mechanical characteristics and somewhat rapid degradation rate $[60,63,64]$ through enzymatic reaction [65].

To overcome such undesired properties, scaffolds based on natural polymers are usually combined with bioactive materials (e.g., bioceramics) or mechanically strong ones (e.g., synthetic polymers or metals), depending on the area of application (e.g., load-bearing or not). Interestingly, although bioceramics are mechanically weak as well, they tend to increase the overall compressive strength of natural polymer based scaffolds [66].

3.2. Biodegradable Synthetic Polymers. Biodegradable synthetic polymers have generated interest in BTE because of their relatively low cost and ability to be produced in large quantities with long shelf life in comparison to their natural counterparts [37]. The most investigated biomaterials of this group are aliphatic polyesters which include polycaprolactone (PCL), polylactic acid (PLA), polyglycolic acid (PGA), and their copolymer poly(lactic-co-glycolic) acid (PLGA).

Polycaprolactone (PCL) is the most popular aliphatic polyester in medical applications; it has been used in medical devices for the last 30 years [35] and has been investigated in craniofacial repair [67]. PCL is an excellent candidate for BTE applications due to its biocompatibility [68], suitability for various scaffold fabrication techniques [69], remarkably slow degradation rate, and mechanical stability [40]. It is suggested that the latter two traits might allow for a better maintenance of generated bone volume and its contour over time. However, PCL is hydrophobic in nature [70] which is also responsible for the inferior cell affinity and poor cellular responses and interactions to the surface [71]. Similar to PCL, polylactic acid (PLA) and poly(lactic-co-glycolic acid) (PLGA) are hydrophobic while polyglycolic acid (PGA) is hydrophilic, keeping in mind that these polymers still have higher rates of degradation in comparison to PCL [72]. But, in general, aliphatic polyesters display a slow degradation rate in correlation to natural polymers and bioceramics [73]. Synthetic polymers degrade by hydrolysis [65] which can be in the form of bulk degradation or surface erosion $[74,75]$. Most of the available polyesters degrade by the former mechanism [76] characterized by hydrolysis within the interior part of the biomaterial, resulting in an empty shell formation, while the size is maintained for a considerable amount of time [77]. This feature is considered appealing for scaffold utilization as a bone graft substitute and less suitable for drug-delivery purposes. Still, aliphatic polyesters release acidic byproducts upon degradation, which can result in tissue necrosis and subsequent scaffold failure with chronic exposure [11]. Therefore, they are usually combined with bioceramics that enhance the bioactivity of a construct and tend to neutralize the acidic byproducts by elevating the overall $\mathrm{pH}$ value for the scaffold [78] to maintain tissue health. Counteracting acidic byproducts and overall $\mathrm{pH}$ buffering can also be achieved when polyesters are combined with metals [79]. Despite the acidic byproducts and the lack of bioactivity, aliphatic polyesters are moldable for fabrication into the required shapes and have good mechanical properties $[80,81]$.

3.3. Bioceramics. Bioceramics are inorganic biomaterials constituting different categories, among which are calcium phosphate bioceramics and bioactive glass with very welldocumented applications as bone fillers in the dental field [82]. Calcium phosphate bioceramics enclose hydroxyapatite (HAp), tricalcium phosphate ( $\alpha$-TCP and $\beta$-TCP), and biphasic calcium phosphate (BCP), all of which can also be in the form of injectable cement materials (pastes) that are moldable and easy to handle and harden when left in situ. Moldable calcium phosphate materials allow for intimate adaptation to complex defects, which is difficult to accomplish with conventional bone grafting materials [83].

Bioceramics are attracting more attention in bone reconstruction due to their unlimited availability, bioactivity, excellent biocompatibility, hydrophilicity, similarity to native bone inorganic components, osteoconductivity [29], and reported potential osteoinductivity [84], which is the ability to induce ectopic bone formation by instructing the surrounding in vivo environment to do so [85]. This potential activity can be attributed either to the surface of bioceramics which absorbs and exhibits osteoinductive factors or to the gradual 
release of calcium and phosphate ions into the surrounding environment, subsequently stimulating the differentiation of osteoprogenitor cells into osteoblasts. Still, both theories are yet to be confirmed [86]. The importance of incorporating calcium phosphates in 3D scaffolds for alveolar bone regeneration has already been demonstrated in the literature [34].

The most investigated calcium phosphate ceramic in BTE is hydroxyapatite (HAp) because it shares the same chemical composition of native bone minerals, which positively influences adhesion and proliferation of osteoblasts [87]. Despite this important feature, HAp takes a long time to degrade when in the "crystalline form" in vivo, causing the remaining particles to impede complete bone formation and increase the risk for infection and exposure in oral and maxillofacial regions [88]. Consequently, applications of crystalline HAp are being eventually substituted by amorphous hydroxyapatite, which has a faster degradation rate [89]. Modification of HAp degradation rate can also be achieved by its combination with other biomaterials of faster kinetics, such as natural polymers [90].

The second most widely studied calcium phosphate ceramic is $\beta$-tricalcium phosphate ( $\beta$-TCP), because of its ability to form a strong bone-calcium phosphate bond [84] and its faster degradation rate [9]. Interestingly, when tricalcium phosphate is combined with HAp, a mixture termed biphasic calcium phosphate (BCP) is produced [91]. In comparison to other calcium phosphate ceramics, $\mathrm{BCP}$ has significant advantages in terms of controlled bioactivity, stability, while promoting bone ingrowth especially in large bone defects [92], and controllable degradation rate [93] as $\mathrm{BCP}$ has a higher degradation rate than HAp, yet slower than that of $\beta$-TCP [94].

Another biomaterial that belongs to bioceramics and is investigated in BTE is bioactive glass (BG), which is a silicon oxide with substituted calcium [18]. When exposed to body fluids, a layer of calcium phosphate forms on the surface of bioactive glass, which chemically binds to bone [95]. The specific type of bioglass used as a synthetic graft in intraoral applications (termed 45S5 Bioglass ${ }^{\circledR}$ ) [18] has a very slow degradation rate because it converts to a HAp-like material in the physiologic environment $[96,97]$. Typically, bioceramics degrade via multiple mechanisms: physiochemical dissolution accompanied by possible phase transformation, multinucleated cell-mediated degradation, and mechanical fragmentation due to loss of structural integrity by the two former mechanisms [76].

Although bioceramics have inviting qualities, they are extremely brittle and difficult to shape into the desired structures because of their stiffness and low flexibility and moldability [98]. They have weak mechanical strength [99] and fracture toughness [100], which limit their applications to non-load-bearing areas. However, their combination with mechanically strong biomaterials, such as synthetic polyesters or metals, tends to eliminate brittleness, difficulty in shaping, and weak mechanical strength [101, 102].

3.4. Metals. Metallic biomaterials are extensively applied in dental and orthopaedic fields to support the replacement of lost bone structures because of their excellent mechanical properties $[103,104]$; they display high strength, toughness, and hardness, in comparison to polymers and ceramics, making them suitable for applications in loadbearing areas [105]. It is reported that metals enhance the mechanical properties of a scaffold by decreasing the pore size [106].

Within this group of biomaterials, titanium and titanium alloys are encouraged in bone regeneration due to their high biocompatibility, appropriate mechanical properties, and elasticity [107]. Different studies reported that titanium-based 3D scaffolds display good hydrophilicity, which enhances mineral deposition and encourages cell attachment and proliferation in vitro [107] and new bone formation without any signs of inflammation or necrosis in vivo [108].

Nonetheless, lack of biodegradability of titanium and titanium alloys is a major disadvantage and might discourage their applications in bone regeneration due to the need of a second surgery for removal, which can compromise patient satisfaction and increase health care costs [103].

In the past decade, magnesium and magnesium alloys have been thoroughly researched and found to be extremely appealing materials for orthopaedic applications [103] with great potential in BTE; they have mechanical properties close to native bone and are completely biodegradable [103] which eliminates the need for a second surgery to retrieve the scaffold. Although magnesium and magnesium alloys degrade by corrosion [109], their byproducts are biocompatible and do not elicit adverse reactions that could negatively affect surrounding tissues [110].

Magnesium and its alloys are osteoconductive, play a role in cell attachment [103], and tend to increase the expression of osteogenic markers in vitro [111]. Although pure magnesium has a rapid rate of degradation in vivo [112], this can be controlled through the utilization of magnesium alloys [113] or by coating pure magnesium with titanium [114] or ceramics [115]. Similar to natural and synthetic polymers, metals lack bioactivity.

In regard to all the previously described biomaterials, each has remarkable characteristics and individual limitations. Henceforth, it is very common to combine two or more different biomaterials to produce a "synergistic effect" in the overall resulting properties [116] and improve the mechanical, biological, and degradation kinetics of a scaffold [117]. Additionally, bone tissue is made of organic and inorganic components [118], thereby making it more difficult for one biomaterial to simulate the complex bone tissue environment and possess the required characteristics of the target tissue [21]. These scaffolds are referred to as "composite" or "hybrid" and whenever three biomaterials are incorporated the term "ternary" can be used. Composite scaffolds used for BTE applications are divided into "polymer/ceramic," "ceramic/metal," and "polymer/metal." The former type is the most popular among composites and has been thoroughly studied by researchers in the orthopaedic field for the last five years [119]. However, the literature confirms that various composite scaffolds support attachment, proliferation, and differentiation of osteoblasts while maintaining the final shape of newly formed bone [119]. 
Composites, whether ternary or not, consist of a major component (matrix) and minor components (filler); the material which constitutes more than $50 \%$ of the blend is considered the major element, while the material/materials that are less than $50 \%$ represent the minor component [120].

\section{Advances in 3D Scaffold Fabrication Techniques}

Different techniques are employed in the fabrication of $3 \mathrm{D}$ scaffolds, with the conventional methods including particle leaching, gas foaming, freeze drying, phase separation, fiber meshes/fiber bonding, melt molding, and solution casting [14]. However, heterogeneities in pore size, porosity, interconnectivity, and architecture are unavoidable with these techniques, which can complicate drawing conclusions from experiments that assess the effect of scaffold properties on newly formed tissues [121]. Moreover, these techniques might not be applicable for the fabrication of a custom-made scaffold with finely tuned architecture that replicates the complexity of native tissues and precisely conforms to the shape of a certain defect.

With the development of solid-freeform fabrication (SFF) techniques, also known as rapid prototyping (RP), it became possible to create scaffolds with precise external shape, internal morphology, and "reproducible" three-dimensional architecture, despite their complexity [122].

These technologies represent additive manufacturing as they build complex structures layer by layer by "3D printing," with one of the following techniques: inkjet printing, laserassisted printing (e.g., Selective Laser Sintering (SLS) and Stereolithography (SLA)), and extrusion printing (e.g., fused deposition modeling (FDM)) [123]. Each printing method is compatible with specific biomaterials and differs in resolution. For example, laser-assisted methods enable printing of diverse biomaterials with wide range viscosities [124]. Such diversity overcomes the limitations of inkjet printing in which low-viscosity inks are needed to prevent clogging of the nozzle of the printing machine that would eventually compromise printing quality, while extrusion printing is restricted to thermoplastic biomaterials such as PCL [123, 125]. In regard to bioprinting, inkjet, laser-assisted, and extrusion-based techniques are utilized in printing of living cells and constructs [123]. As a consequence, these technologies can be further explored in cell encapsulation and cellbased therapies, especially that they allow for controlled positioning of cells with precision, which could mimic the tissue interface and the surrounding microenvironment. However, these applications are generally reserved to hydrogel scaffolds [126], made of natural or synthetic polymers [125]. Different $3 \mathrm{D}$ printing methods are demonstrated in Figure 2 [123].

These new techniques utilize computer-aided design (CAD) and computer-assisted manufacturing (CAM) technologies to $3 \mathrm{D}$-print a desired structure based on a $\mathrm{CAD}$ file that has already defined the exact dimensions of a scaffold [126]. This approach can be applicable in fabricating constructs that conform to a specific anatomical shape; in a typical clinical case scenario, CAD models are produced based on images from computed tomography (CT) scans of a patient-specific bone defect to develop a "custom-made" bone graft substitute which could be helpful in regenerating defects with complex geometry [127] as illustrated in Figure 3 [128]. Image-based 3D-printed scaffold following this scheme displayed promising results in preclinical investigations in periodontal regeneration with the need of further assessment for future employment in clinical practice $[46,128]$. In the literature, few studies have focused on the concept of custommade scaffolds for alveolar bone regeneration, by using subtractive technology (milling of a commercially available block, dictated by CAD/CAM technologies), which might not be as sophisticated due to the lack of layer-by-layer addition [129-131].

Although RP techniques are capable of producing constructs with satisfying mechanical strength by precisely controlling the overall geometrical design and porosity, these characteristics can still be limited by the machine's resolution and material repertoire. Due to the lack of sufficient resolution to fabricate nano- and submicrometer structures, a combination of RP techniques with different fabrication methods such as electrospinning [132] has been proposed to allow for the construction of efficient biomimetic constructs.

\section{Applications of 3D-Printed and/or Compartmentalized Scaffolds in Alveolar Bone and Periodontal Tissue Regeneration}

With the increased need for "optimal" tissue regeneration, "3D-printed" scaffolds have been recently investigated in different periodontal applications: guided bone regeneration (GBR), guided tissue regeneration (GTR), vertical bone augmentation, sinus augmentation, and socket preservation, showing variable outcomes of success.

PCL has been the most utilized biomaterial in these applications, probably because of its well-documented positive outcomes in hard tissue regeneration in the field of orthopaedics [119].

Regarding periodontal tissue regeneration, a novel anatomically shaped human-molar and rat-incisor 3Dprinted PCL/HAp scaffold showed promising results in terms of inducing regeneration by "cell homing" instead of cell delivery in a rat model [133]. In another rat model $[46,128]$, the concept of "compartmentalization" was applied to achieve regeneration of periodontal ligament, cementum, and alveolar bone, by utilizing a custom-made 3D-printed PCL scaffold which enclosed an alveolar bone interface and a PDL interface with fiber-guiding architecture. The biphasic construct allowed not only for the regeneration of obliquely oriented periodontal fibers, cementum-like tissue, and alveolar bone, but also for a greater control of tissue infiltration when compared to random porous scaffolds. Similarly, multiphasic periodontal tissue regeneration was achieved with a $3 \mathrm{D}$-printed PCL/HAp triphasic scaffold that allowed for spatiotemporal delivery of multiple proteins, in vivo [134].

Recently, a biphasic PCL scaffold utilizing two scaffold fabrication techniques and cell sheet technology was 


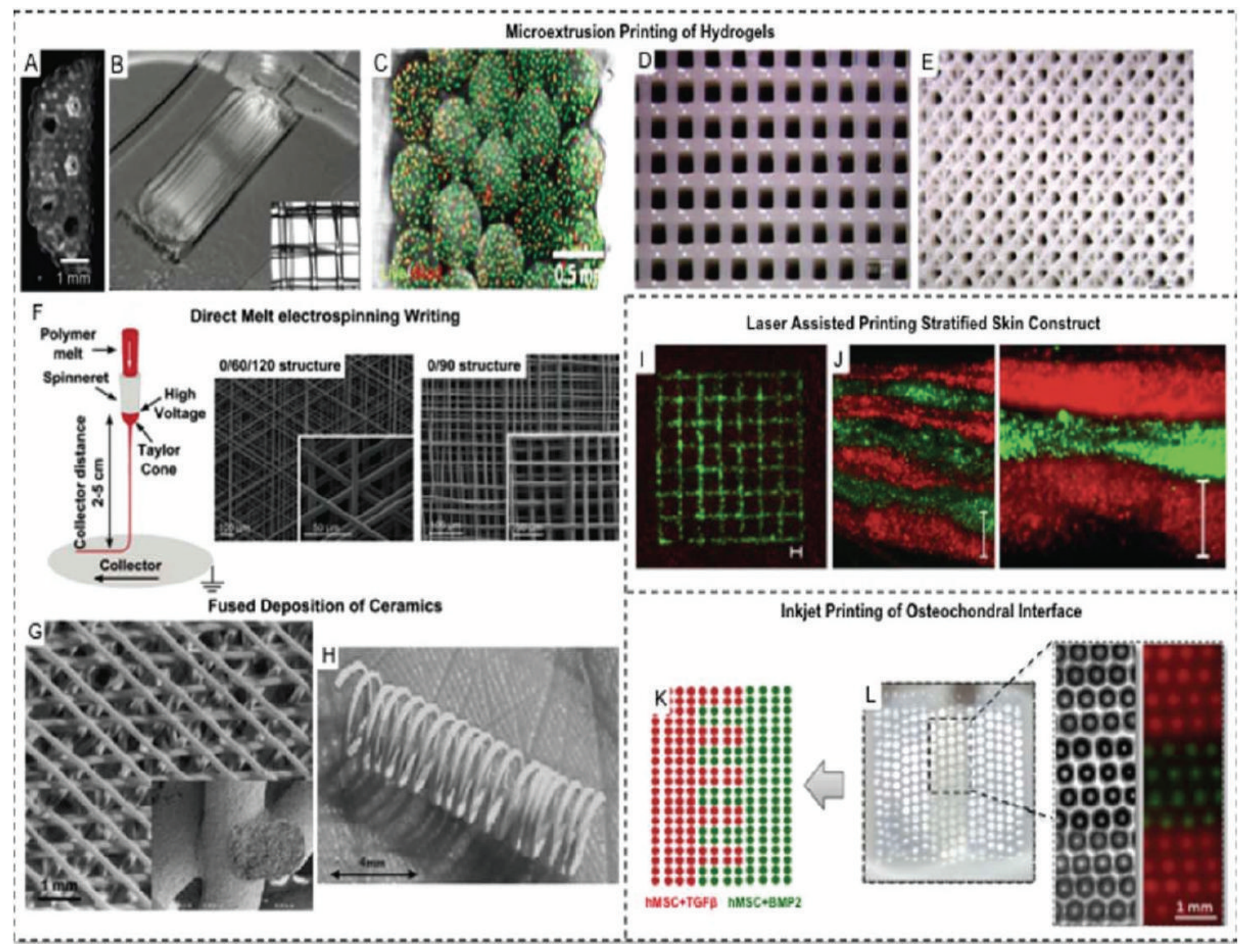

FIGURE 2: Different 3D printing methods used to manufacture 3D scaffolds for various applications. Courtesy of Obregon et al., 2015 [123].

investigated in the regeneration of the alveolar bone and periodontal tissues [33]. In fact, cell sheet technology was tested as a part of the scaffold to provide biomechanical support during wound healing process, which was lacking in a material-free approach of cell sheet technology in periodontal regeneration [135]. The scaffold enclosed two compartments manufactured by two different techniques and of different biomaterials: the bone compartment was constructed from $\beta$-TCP/PCL by fused deposition modeling (FDM) and then thermally incorporated with an electrospun PCL membrane enclosing cell sheets, representing the PDL compartment. After being tested in a subcutaneous rat model, results demonstrated successful regeneration of cementum, alveolar bone, and periodontal ligament. Early bone markers confirmed that FDM bone interface promoted early bone formation. However, there was no functional orientation of the PDL fibers, as no specific cell oriented architecture was contained in the design. To address this finding, the researchers developed a second generation of the same scaffold [34] but with specific modifications of the PDL compartment, by including superimposed concentrically oriented rings in the membrane, fabricated by melt electrospinning to allow for some level of tissue organization. This interface was also more porous to improve cell interactions and vascularization. The bone compartment was modified to enhance alveolar bone regeneration by coating the $\beta$-TCP/PCL construct with calcium phosphate $(\mathrm{CaP})$. By employing the same animal model, results revealed higher bone formation with improved PDL fiber orientation and vessel ingrowth.

Despite the promising results in vivo, 3D-printed PCLbased scaffolds showed less promising outcomes in clinical studies.

A "prefabricated" 3D PCL scaffold printed by FDM was tested for socket preservation in a randomized clinical trial [35]. Although the scaffold maintained the ridge height better after 6 months, this finding can be expected because no filler was used in the control group. The efficacy of PCLbased scaffolds as space fillers in socket preservation should be interpreted with caution, because comparison with other socket preservation techniques is still lacking. Most importantly, the scaffolds showed minimal signs of degradation 6 months following intervention and fibrous invasion was reported in one patient due to manual shaping for friction fit within the extraction socket. One might conclude that 


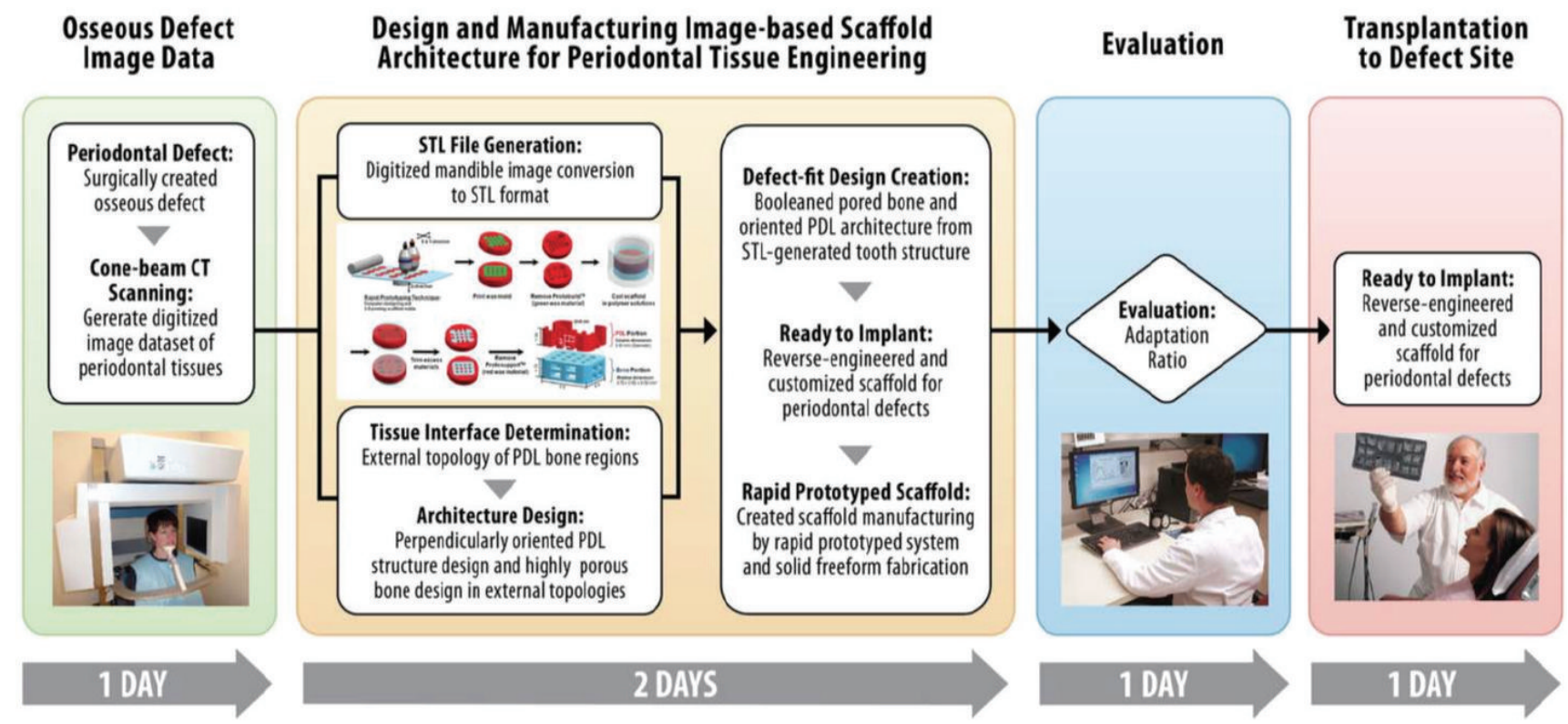

FIGURE 3: CAD models are produced based on computed tomography (CT) scans of a patient-specific bone defect to develop a custom-made bone graft substitute. Courtesy of Park et al., 2014 [128].

"custom-made" 3D-printed PCL scaffolds based on medical imaging could show more favorable results by allowing precise adaptation to the bony defect. However, adverse outcomes were reported when a custom-made image-based 3D fiber-guiding PCL/HAp scaffold printed by SLS was applied in GTR in a recent case report, as shown in Figure 4 [136]. After thirteen months of scaffold implantation, soft tissue dehiscence was reported with histological and molecular weight analysis revealing that almost $76 \%$ of the scaffold mass remained with minimal bone repair. This result can be interpreted by the very slow degradation profile of PCL in addition to its inferior cell affinity and weak osteoconductive activity. The final outcome might have also been compromised due to the low resolution of the applied $3 \mathrm{D}$ printing technology. Interestingly, one might attribute the end result to the acidic byproducts upon degradation, as well. Nonetheless, this matter is debatable, as some data in the literature have revealed that metabolic pathways easily remove PCL byproducts and thus PCL does not produce a local acidic environment as other aliphatic polyesters [137, 138].

The slow degradation of PCL has been considered appealing in hard tissue regeneration [40], but this might be valid for orthopaedic applications only, because there are key differences in the behaviour between long bones and alveolar bone as remodeling is slower in the former in comparison to the latter [139]. Although it is very well documented that bioceramics tend to control the degradation rate of polyesters [140], the percentage of HAp that was combined with PCL in this case report (4\%) might not have been sufficient to accelerate the degradation profile. As a matter of fact, accelerated degradation of PCL was achievable with a much higher percentage of HAp in an in vitro investigation [140].
Interestingly, this fiber-guiding scaffold model in GTR was successful in preclinical studies on rats $[46,128]$. The discrepancy in results could be due to the differences between rats and humans in terms of healing window, anatomic structures, and host responses [141].

Another biomaterial that has been widely tested as part of 3D scaffolds for periodontal applications is bioceramics, mainly in sinus and bone augmentation procedures. In a sheep animal model, a prefabricated 3D-printed scaffold, made of biphasic ceramic ( $\alpha$-TCP + HAp), was compared to bovine bone (Bio-Oss) and particulate $\beta$-TCP for vertical bone augmentation [142]. The scaffold eliminated the need for membranes and provided better mechanical support to the newly formed tissues, which can be explained by the fact that when $\alpha$-TCP comes into contact with body fluids, it converts to HAp which has a very slow degradation rate. Similarly, a 3D-printed BCP scaffold (HAp (30\%), $\beta$-TCP (60\%), and $\alpha$-TCP (10\%)) showed favorable outcomes as a bone graft substitute for sinus augmentation in vivo in terms of abundant deposition of newly formed bone tissue within the biomaterial pores, which could be promising in future clinical applications [143].

Specific conclusions can be extrapolated from the previous studies about the use of certain biomaterials in scaffolding for various periodontal applications. For example, the use of PCL as the only biomaterial in a scaffold could be discouraged mainly due to its slow degradation rate which can lead to wound dehiscence and subsequent failure of tissue regeneration, also due to its inferior cell affinity [71]. If combined with bioceramics, an increase in the weight percentage of the bioceramic should be utilized to accelerate the degradation profile. Likewise, increased porosity of the bulk scaffold construct can assist with more rapid tissue ingrowth that can further drive the degradation process. 

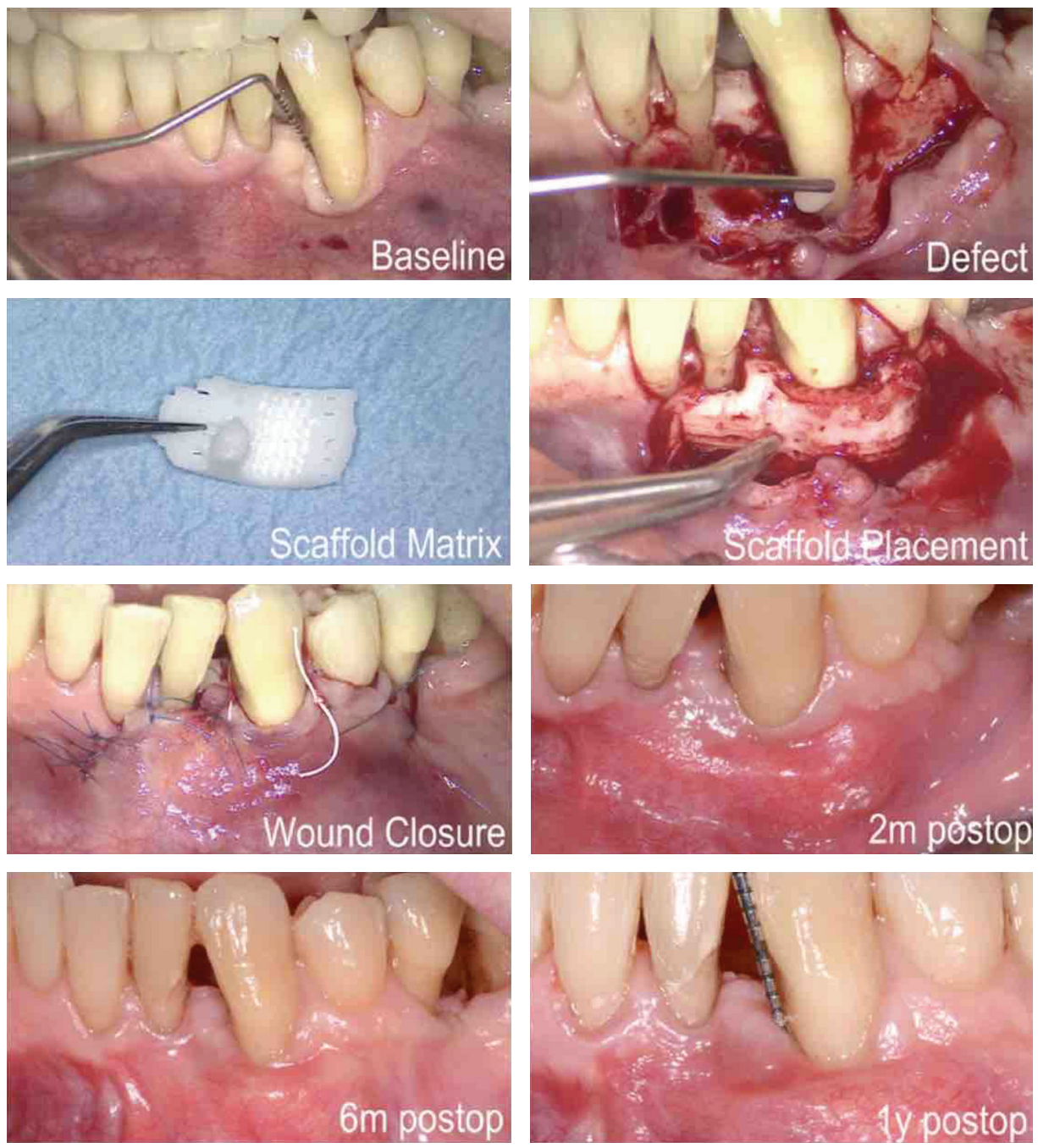

FIGURE 4: Custom-made 3D-printed PCL/HAp scaffold based on images from computed tomography (CT) scans and combined with CAD/CAM technologies for periodontal tissue regeneration. Courtesy of Rasperini et al., 2015 [136].

Other aliphatic polyesters might be discouraged as well due to their acidic byproducts unless counteracted by the combination of bioceramics or metals. In a recent in vitro/in vivo investigation, magnesium/PLGA scaffold was applied in socket preservation, in which magnesium was able to counteract the acidic degradation of PLGA, thus decreasing the risk for tissue inflammation and eventually enhancing osteogenesis [79]. Still, it should be kept in mind that the ideal percentage of biomaterials to eliminate the risk of adverse effects may be difficult to determine for clinical uses.

Regarding GTR, where contact with bacteria and exposure are more likely to occur, natural polymers could be the best choice for this specific application, such as chitosan which has antibacterial properties that could decrease the chance of bacterial contamination and subsequent exposure. Gelatin can also be recommended in this application, and it has already been investigated in vitro as the biomaterial of a "periodontally inspired" scaffold, created by directional freeze-casting [144]. Despite having relatively low compressive resistance, gelatin displayed attractive biological properties because intrinsic cell interactions with the scaffold surface are still possible in the presence of adhesive RGD motifs, making cell affinity and growth more significant [145]. To overcome the mechanical weakness of gelatin, incorporation of this platform into the previously described synthetic polymer-based, fiber-guiding 3D scaffold system $[46,128]$ has been proposed.

It must be taken into consideration that natural polymers must be combined with mechanically strong materials; in GTR applications, the scaffold serves a dual role: a grafting material and a membrane. Since space maintenance is required for periodontal regeneration, it is essential to utilize a mechanically strong scaffold.

For applications in alveolar bone regeneration, augmentation, and socket preservation, scaffolds made of bioceramics can be recommended. Nevertheless, using bioceramics alone can be questionable for clinical applications, because of their weak mechanical properties. To overcome such limitations, bioceramics can be combined with mechanically strong biomaterials as mentioned earlier. 
In non-load-bearing areas, collagen could be the preferred biomaterial in such combination. Better outcomes are to be expected with the incorporation of collagen because a bioceramic/collagen mix is the closest replicate of the ECM composition of native bone [146].

Specifically, the combination of collagen with hydroxyapatite is encouraged in bone tissue regeneration [146] due to the compositional similarities to native tissue and reasonable degradation rates for clinical uses [90].

In bone tissue regeneration, care must be taken that this process might take a long time in case of severe ridge resorption, because bone regeneration through scaffolds commences at the peripheries, where contact points between the biomaterial and native bone exist. However, this can be resolved with advances in tissue engineering and further investigations, by creating different points of bone nucleation through engineering with stem/osteoprogenitor cells [143].

To this end, studies on 3D-printed scaffolds in the periodontal field have focused on biomaterials, new and/or functional tissue formation, and spatial organization mainly when multiple tissue regeneration was attempted. Accordingly, other characteristics still need to be addressed more thoroughly, such as vascularization, analysis of landscape topography, and degradation profile and kinetics. Moreover, "image-based" 3D-printed scaffolds must be investigated in alveolar bone regeneration prior to placement of dental implants, as there are no published studies on this specific use.

\section{Recommendations and Future Directions}

BTE is based not only on cellular and molecular events and interactions, but also on the development of biomaterials and scaffolds with prescribed biomechanical properties, representing a fundamental part of the BTE paradigm.

Dental literature on 3D scaffolds and related biomaterials as alternative to bone grafts is still scarce, with extremely limited clinical trials. Validation of the efficacy of scaffolds tested in animal models is obligatory, because the already published results are not representative due to small defects, graft size, and also a completely different healing process in small animals. Randomized controlled clinical trials are mandatory, with adequate number of patients and long-term follow-up of implant therapy following scaffold employment in preimplant augmentation procedures. Thorough evaluation of biological and mechanical properties, as well as degradation profiles of $3 \mathrm{D}$ scaffolds in periodontal applications, is needed. The effect of 3D scaffolds on "blood clot stabilization" should be assessed, as it is an important prognostic factor in alveolar bone regeneration [7]. Moreover, scaffolds should be tested as part of a complete tissue regeneration protocol, in combination with new techniques of soft tissue management which is the key for optimum regenerative outcomes [147]. Due to the existing limitations of scaffold fabrication techniques, investigations of technique combination must be evaluated as an acceptable modality for producing scaffolds with clearcut scales on different levels. As scaffold stabilization represents an important factor in preventing micromotion and compromised regeneration outcomes, different stabilization techniques could be investigated as well (press-fit graft, fibrin glue) since fixation with screws and pins might compromise the scaffold integrity, especially in large defects.

\section{Conclusions}

Scaffolding matrices are an attractive alternative to bone replacement grafts in surgical procedures related to endosseous implant placement, that is, vertical and/or horizontal bone augmentation, socket preservation, and sinus augmentation. Scaffolding matrices can also be used as a membrane and grafting material in periodontal tissue regeneration. A scaffold should be biocompatible, biodegradable, and bioactive and should be made of a hybrid of biomaterials, as the combination of different biomaterials is superior to a pure material, mechanically and biologically. Regardless, it is still unknown which combination of materials is optimal for alveolar bone regeneration. Much work lies ahead to translate the promising results of preclinical studies into clinical reality.

\section{Competing Interests}

Sophia P. Pilipchuk and William V. Giannobile hold intellectual property related to $3 \mathrm{D}$-printed scaffolds. The other authors declare no competing interests.

\section{Acknowledgments}

This work was partially supported by the University of Milan, Italy, NIH/NIDCR DE 13397, and National Science Foundation Fellowship (DGE 1256260).

\section{References}

[1] F. Javed, H. B. Ahmed, R. Crespi, and G. E. Romanos, "Role of primary stability for successful osseointegration of dental implants: factors of influence and evaluation," Interventional Medicine and Applied Science, vol. 5, no. 4, pp. 162-167, 2013.

[2] B. S. McAllister and K. Haghighat, "Bone augmentation techniques," Journal of Periodontology, vol. 78, no. 3, pp. 377-396, 2007.

[3] I. Rocchietta, F. Fontana, and M. Simion, "Clinical outcomes of vertical bone augmentation to enable dental implant placement: a systematic review," Journal of Clinical Periodontology, vol. 35, supplement 8, pp. 203-215, 2008.

[4] M. Esposito, M. G. Grusovin, P. Felice, G. Karatzopoulos, H. V. Worthington, and P. Coulthard, "Interventions for replacing missing teeth: horizontal and vertical bone augmentation techniques for dental implant treatment," Cochrane Database of Systematic Reviews, vol. 4, Article ID CD003607, 2009.

[5] S. S. Jensen and H. Terheyden, "Bone augmentation procedures in localized defects in the alveolar ridge: clinical results with different bone grafts and bone-substitute materials," The International Journal of Oral \& Maxillofacial Implants, vol. 24, supplement 1, pp. 218-236, 2009.

[6] M. Esposito, G. Cannizarro, E. Soardi, G. Pellegrino, R. Pistilli, and P. Felice, "A 3-year post-loading report of a randomised controlled trial on the rehabilitation of posterior atrophic mandibles: short implants or longer implants in vertically augmented bone?" European Journal of Oral Implantology, vol. 4, no. 4, pp. 301-311, 2011. 
[7] G. Pellegrini, G. Pagni, and G. Rasperini, "Surgical approaches based on biological objectives: GTR versus GBR techniques," International Journal of Dentistry, vol. 2013, Article ID 521547, 13 pages, 2013.

[8] G. Pagni, D. Kaigler, G. Rasperini, G. Avila-Ortiz, R. Bartel, and W. V. Giannobile, "Bone repair cells for craniofacial regeneration," Advanced Drug Delivery Reviews, vol. 64, no. 12, pp. 1310-1319, 2012.

[9] A. Oryan, S. Alidadi, A. Moshiri, and N. Maffulli, "Bone regenerative medicine: classic options, novel strategies, and future directions," Journal of Orthopaedic Surgery and Research, vol. 9, no. 1, article 18, 2014.

[10] R. J. O’Keefe and J. Mao, "Bone tissue engineering and regeneration: from discovery to the clinic-an overview," Tissue Engineering Part B: Reviews, vol. 17, no. 6, pp. 389-392, 2011.

[11] A. R. Amini, C. T. Laurencin, and S. P. Nukavarapu, "Bone tissue engineering: recent advances and challenges," Critical Reviews in Biomedical Engineering, vol. 40, no. 5, pp. 363-408, 2012.

[12] J. P. Fisher and A. H. Reddi, "Functional tissue engineering of bone: signals and scaffolds," in Topics in Tissue Engineering, N. Ashammakhi and P. Ferretti, Eds., pp. 1-29, University of Oulu, Oulu, Finland, 1st edition, 2003.

[13] Y. Ikada, "Challenges in tissue engineering," Journal of the Royal Society Interface, vol. 3, no. 10, pp. 589-601, 2006.

[14] Y. Kinoshita and H. Maeda, "Recent developments of functional scaffolds for craniomaxillofacial bone tissue engineering applications," The Scientific World Journal, vol. 2013, Article ID 863157, 21 pages, 2013.

[15] G. D. Nicodemus and S. J. Bryant, "Cell encapsulation in biodegradable hydrogels for tissue engineering applications," Tissue Engineering Part B: Reviews, vol. 14, no. 2, pp. 149-165, 2008.

[16] A. Murua, A. Portero, G. Orive, R. M. Hernández, M. de Castro, and J. L. Pedraz, "Cell microencapsulation technology: towards clinical application," Journal of Controlled Release, vol. 132, no. 2, pp. 76-83, 2008.

[17] S. J. Bryant and K. S. Anseth, "Controlling the spatial distribution of ECM components in degradable PEG hydrogels for tissue engineering cartilage," Journal of Biomedical Materials Research Part A, vol. 64, no. 1, pp. 70-79, 2003.

[18] S. P. Pilipchuk, A. B. Plonka, A. Monje et al., "Tissue engineering for bone regeneration and osseointegration in the oral cavity," Dental Materials, vol. 31, no. 4, pp. 317-338, 2015.

[19] C. J. Damien and J. R. Parsons, "Bone graft and bone graft substitutes: a review of current technology and applications," Journal of Applied Biomaterials, vol. 2, no. 3, pp. 187-208, 1991.

[20] K. Seunarine, N. Gadegaard, M. Tonnen, D. O. Meredith, M. O. Riehle, and C. D. W. Wilkinson, "3D polymer scaffolds for tissue engineering," Nanomedicine, vol. 1, no. 3, pp. 281-296, 2006.

[21] G. Castillo-Dalí, R. Velázquez-Cayón, M. A. Serrera-Figallo, A. Rodríguez-González-Elipe, J.-L. Gutierrez-Pérez, and D. Torres-Lagares, "Importance of poly(lactic-co-glycolic acid) in scaffolds for guided bone regeneration: a focused review," The Journal of Oral Implantology, vol. 41, no. 4, pp. e152-e157, 2015.

[22] H. Li and J. Chang, "Fabrication and characterization of bioactive wollastonite/PHBV composite scaffolds," Biomaterials, vol. 25, no. 24, pp. 5473-5480, 2004.

[23] J. M. Goddard and J. H. Hotchkiss, "Polymer surface modification for the attachment of bioactive compounds," Progress in Polymer Science, vol. 32, no. 7, pp. 698-725, 2007.
[24] W. Hoffmann, T. Bormann, A. Rossi et al., "Rapid prototyped porous nickel-titanium scaffolds as bone substitutes," Journal of Tissue Engineering, vol. 5, pp. 1-14, 2014.

[25] K. Cheng and W. S. Kisaalita, "Exploring cellular adhesion and differentiation in a micro-/nano-hybrid polymer scaffold," Biotechnology Progress, vol. 26, no. 3, pp. 838-846, 2010.

[26] J. Park, S. Bauer, K. Von der Mark, and P. Schmuki, "Nanosize and vitality: $\mathrm{TiO}_{2}$ nanotube diameter directs cell fate," Nano Letters, vol. 7, no. 6, pp. 1686-1691, 2007.

[27] T. J. Webster and T. A. Smith, "Increased osteoblast function on PLGA composites containing nanophase titania," Journal of Biomedical Materials Research-Part A, vol. 74, no. 4, pp. 677686, 2005.

[28] S. J. Hollister, R. D. Maddox, and J. M. Taboas, “Optimal design and fabrication of scaffolds to mimic tissue properties and satisfy biological constraints," Biomaterials, vol. 23, no. 20, pp. 4095-4103, 2002.

[29] J. R. Woodard, A. J. Hilldore, S. K. Lan et al., "The mechanical properties and osteoconductivity of hydroxyapatite bone scaffolds with multi-scale porosity," Biomaterials, vol. 28, no. 1, pp. 45-54, 2007.

[30] C. H. Park, H. F. Rios, Q. Jin et al., "Biomimetic hybrid scaffolds for engineering human tooth-ligament interfaces," Biomaterials, vol. 31, no. 23, pp. 5945-5952, 2010.

[31] V. Karageorgiou and D. Kaplan, "Porosity of 3D biomaterial scaffolds and osteogenesis," Biomaterials, vol. 26, no. 27, pp. 5474-5491, 2005.

[32] S. Bose, M. Roy, and A. Bandyopadhyay, "Recent advances in bone tissue engineering scaffolds," Trends in Biotechnology, vol. 30, no. 10, pp. 546-554, 2012.

[33] C. Vaquette, W. Fan, Y. Xiao, S. Hamlet, D. W. Hutmacher, and S. Ivanovski, "A biphasic scaffold design combined with cell sheet technology for simultaneous regeneration of alveolar bone/periodontal ligament complex," Biomaterials, vol. 33, no. 22, pp. 5560-5573, 2012.

[34] P. F. Costa, C. Vaquette, Q. Zhang, R. L. Reis, S. Ivanovski, and D. W. Hutmacher, "Advanced tissue engineering scaffold design for regeneration of the complex hierarchical periodontal structure," Journal of Clinical Periodontology, vol. 41, no. 3, pp. 283-294, 2014.

[35] B. T. Goh, L. Y. Teh, D. B. P. Tan, Z. Zhang, and S. H. Teoh, "Novel 3D polycaprolactone scaffold for ridge preservationa pilot randomised controlled clinical trial," Clinical Oral Implants Research, vol. 26, no. 3, pp. 271-277, 2015.

[36] G. F. Muschler, C. Nakamoto, and L. G. Griffith, "Engineering principles of clinical cell-based tissue engineering," The Journal of Bone \& Joint Surgery-American Volume, vol. 86, no. 7, pp. 1541-1558, 2004.

[37] B. Dhandayuthapani, Y. Yoshida, T. Maekawa, and D. S. Kumar, "Polymeric scaffolds in tissue engineering application: a review," International Journal of Polymer Science, vol. 2011, Article ID 290602, 19 pages, 2011.

[38] H. I. Chang and Y. Wang, "Cell responses to surface and architecture of tissue engineering scaffolds," in Regenerative Medicine and Tissue Engineering-Cells and Biomaterials, D. Eberli, Ed., pp. 569-588, In-Tech, Rijeka, Croatia, 2011.

[39] F. J. O’Brien, "Biomaterials \& scaffolds for tissue engineering," Materials Today, vol. 14, no. 3, pp. 88-95, 2011.

[40] A. G. Mitsak, J. M. Kemppainen, M. T. Harris, and S. J. Hollister, "Effect of polycaprolactone scaffold permeability on bone regeneration in vivo," Tissue Engineering Part A, vol. 17, no. 13-14, pp. 1831-1839, 2011. 
[41] D. W. Hutmacher, "Scaffolds in tissue engineering bone and cartilage," Biomaterials, vol. 21, no. 24, pp. 2529-2543, 2000.

[42] A. Yeo, B. Rai, E. Sju, J. J. Cheong, and S. H. Teoh, "The degradation profile of novel, bioresorbable PCL-TCP scaffolds: an in vitro and in vivo study," Journal of Biomedical Materials Research Part A, vol. 84, no. 1, pp. 208-218, 2008.

[43] Q. Chen, C. Zhu, and G. A. Thouas, "Progress and challenges in biomaterials used for bone tissue engineering: bioactive glasses and elastomeric composites," Progress in Biomaterials, vol. 1, article 2, 2012.

[44] L. L. Hench, R. J. Splinter, W. C. Allen, and T. K. Greenlee, "Bonding mechanisms at the interface of ceramic prosthetic materials," Journal of Biomedical Materials Research, vol. 5, no. 6, pp. 117-141, 1971.

[45] S. Ivanovski, C. Vaquette, S. Gronthos, D. W. Hutmacher, and P. M. Bartold, "Multiphasic scaffolds for periodontal tissue engineering," Journal of Dental Research, vol. 93, no. 12, pp. 12121221, 2014.

[46] C. H. Park, H. F. Rios, Q. Jin et al., "Tissue engineering boneligament complexes using fiber-guiding scaffolds," Biomaterials, vol. 33, no. 1, pp. 137-145, 2012.

[47] G. Khang, "Evolution of gradient concept for the application of regenerative medicine," Biosurface and Biotribology, vol. 1, no. 3, pp. 202-213, 2015.

[48] L. S. Nair and C. T. Laurencin, "Biodegradable polymers as biomaterials," Progress in Polymer Science, vol. 32, no. 8-9, pp. 762-798, 2007.

[49] I. M. El-Sherbiny and M. H. Yacoub, "Hydrogel scaffolds for tissue engineering: progress and challenges," Global Cardiology Science and Practice, vol. 2013, no. 3, article 38, 2013.

[50] A. G. Mikos, M. G. Papadaki, S. Kouvroukoglou, S. L. Ishaug, and R. C. Thomson, "Mini-review: islet transplantation to create a bioartificial pancreas," Biotechnology \& Bioengineering, vol. 43, no. 7, pp. 673-677, 1994.

[51] Y. Cao, A. Rodriguez, M. Vacanti, C. Ibarra, C. Arevalo, and C. A. Vacanti, "Comparative study of the use of poly(glycolic acid), calcium alginate and pluronics in the engineering of autologous porcine cartilage," Journal of Biomaterials Science, Polymer Edition, vol. 9, no. 5, pp. 475-487, 1998.

[52] C. D. Sims, P. E. M. Butler, Y. L. Cao et al., "Tissue engineered neocartilage using plasma derived polymer substrates and chondrocytes," Plastic and Reconstructive Surgery, vol. 101, no. 6, pp. 1580-1585, 1998.

[53] C. Perka, R.-S. Spitzer, K. Lindenhayn, M. Sittinger, and O. Schultz, "Matrix-mixed culture: new methodology for chondrocyte culture and preparation of cartilage transplants," Journal of Biomedical Materials Research, vol. 49, no. 3, pp. 305-311, 2000.

[54] K. Y. Lee and D. J. Mooney, "Hydrogels for tissue engineering," Chemical Reviews, vol. 101, no. 7, pp. 1869-1879, 2001.

[55] L. Pastorino, E. Dellacasa, S. Scaglione et al., "Oriented collagen nanocoatings for tissue engineering," Colloids and Surfaces B: Biointerfaces, vol. 114, pp. 372-378, 2014.

[56] A. Aravamudhan, D. M. Ramos, J. Nip et al., "Cellulose and collagen derived micro-nano structured scaffolds for bone tissue engineering," Journal of Biomedical Nanotechnology, vol. 9, no. 4, pp. 719-731, 2013.

[57] M.-F. Côté, G. Laroche, E. Gagnon, P. Chevallier, and C. J. Doillon, "Denatured collagen as support for a FGF-2 delivery system: physicochemical characterizations and in vitro release kinetics and bioactivity," Biomaterials, vol. 25, no. 17, pp. 37613772, 2004.
[58] U. Meyer and H. P. Wiesmann, Bone and Cartilage Engineering, Springer, Berlin, Germany, 2006.

[59] I. Aranaz, M. Mengíbar, R. Harris et al., "Functional characterization of chitin and chitosan," Current Chemical Biology, vol. 3, no. 2, pp. 203-230, 2009.

[60] J. Sun and H. Tan, "Alginate-based biomaterials for regenerative medicine applications," Materials, vol. 6, no. 4, pp. 1285-1309, 2013.

[61] B. M. Holzapfel, J. C. Reichert, J.-T. Schantz et al., "How smart do biomaterials need to be? A translational science and clinical point of view," Advanced Drug Delivery Reviews, vol. 65, no. 4, pp. 581-603, 2013.

[62] M. G. Raucci, V. Guarino, and L. Ambrosio, "Biomimetic strategies for bone repair and regeneration," Journal of Functional Biomaterials, vol. 3, no. 4, pp. 688-705, 2012.

[63] S. J. Florczyk, D.-J. Kim, D. L. Wood, and M. Zhang, "Influence of processing parameters on pore structure of $3 \mathrm{D}$ porous chitosan-alginate polyelectrolyte complex scaffolds," Journal of Biomedical Materials Research Part A, vol. 98, no. 4, pp. 614-620, 2011.

[64] Z. Cao, C. Dou, and S. Dong, "Scaffolding biomaterials for cartilage regeneration," Journal of Nanomaterials, vol. 2014, Article ID 489128, 8 pages, 2014.

[65] R. Lenz, "Biodegradable polymers," in Biopolymers I, R. S. Langer and N. A. Peppas, Eds., vol. 107 of Advances in Polymer Science, pp. 1-40, Springer, Berlin, Germany, 1993.

[66] R. J. Kane, H. E. Weiss-Bilka, M. J. Meagher et al., "Hydroxyapatite reinforced collagen scaffolds with improved architecture and mechanical properties," Acta Biomaterialia, vol. 17, pp. 1625, 2015.

[67] J. E. Gough, P. Christian, C. A. Scotchford, and I. A. Jones, "Craniofacial osteoblast responses to polycaprolactone produced using a novel boron polymerisation technique and potassium fluoride post-treatment," Biomaterials, vol. 24, no. 27, pp. 4905-4912, 2003.

[68] C. G. Pitt, "Poly ( $\varepsilon$-caprolactone) and its copolymers," in Biodegradable Polymers as Drug Delivery Systems, M. Chassin and R. Langer, Eds., pp. 71-119, Dekker, New York, NY, USA, 1990.

[69] J. M. Williams, A. Adewunmi, R. M. Schek et al., "Bone tissue engineering using polycaprolactone scaffolds fabricated via selective laser sintering," Biomaterials, vol. 26, no. 23, pp. 4817-4827, 2005.

[70] Y. Zhu, C. Gao, and J. Shen, "Surface modification of polycaprolactone with poly(methacrylic acid) and gelatin covalent immobilization for promoting its cytocompatibility," Biomaterials, vol. 23, no. 24, pp. 4889-4895, 2002.

[71] M. M. Lim, T. Sun, and N. Sultana, "In Vitro biological evaluation of electrospun polycaprolactone/gelatine nanofibrous scaffold for tissue engineering," Journal of Nanomaterials, vol. 2015, Article ID 303426, 10 pages, 2015.

[72] Q. Chen and G. Thouas, "Bioresorbable polymers," in Biomaterials: A Basic Introduction, p. 346, CRC Press, Boca Raton, Fla, USA, 2015.

[73] L. Yildirimer and A. M. Seifalian, "Three-dimensional biomaterial degradation-material choice, design and extrinsic factor considerations," Biotechnology Advances, vol. 32, no. 5, pp. 984999, 2014.

[74] A. Göpferich, "Mechanisms of polymer degradation and erosion," Biomaterials, vol. 17, no. 2, pp. 103-114, 1996. 
[75] F. von Burkersroda, L. Schedl, and A. Göpferich, "Why degradable polymers undergo surface erosion or bulk erosion," Biomaterials, vol. 23, no. 21, pp. 4221-4231, 2002.

[76] N. L. Davison, F. Barrère-de Groot, and D. W. Grijpma, "Degradation of biomaterials," in Tissue Engineering, C. A. Van Blitterswijk and J. De Boer, Eds., pp. 177-215, Elsevier, 2nd edition, 2015.

[77] S. Li, "Hydrolytic degradation characteristics of aliphatic polyesters derived from lactic and glycolic acids," Journal of Biomedical Materials Research, vol. 48, no. 3, pp. 342-353, 1999.

[78] E. Tamjid, A. Simchi, J. W. C. Dunlop, P. Fratzl, R. Bagheri, and M. Vossoughi, "Tissue growth into three-dimensional composite scaffolds with controlled micro-features and nanotopographical surfaces," Journal of Biomedical Materials ResearchPart A, vol. 101, no. 10, pp. 2796-2807, 2013.

[79] A. Brown, S. Zaky, H. Ray Jr., and C. Sfeir, "Porous magnesium/PLGA composite scaffolds for enhanced bone regeneration following tooth extraction," Acta Biomaterialia, vol. 11, pp. 543-553, 2015.

[80] M. I. Sabir, X. Xu, and L. Li, "A review on biodegradable polymeric materials for bone tissue engineering applications," Journal of Materials Science, vol. 44, no. 21, pp. 5713-5724, 2009.

[81] T. Gong, J. Xie, J. Liao, T. Zhang, S. Lin, and Y. Lin, "Nanomaterials and bone regeneration," Bone Research, vol. 3, article 15029, 2015.

[82] R. Sarkar and G. Banerjee, "Ceramic based bio-medical implants," InterCeram, vol. 59, no. 2, pp. 98-102, 2010.

[83] W. Thein-Han and H. H. K. Xu, "Collagen-calcium phosphate cement scaffolds seeded with umbilical cord stem cells for bone tissue engineering," Tissue Engineering Part A, vol. 17, no. 23-24, pp. 2943-2954, 2011.

[84] R. Z. LeGeros, "Properties of osteoconductive biomaterials: calcium phosphates," Clinical Orthopaedics and Related Research, vol. 395, pp. 81-98, 2002.

[85] T. J. Blokhuis and J. J. C. Arts, "Bioactive and osteoinductive bone graft substitutes: definitions, facts and myths," Injury, vol. 42, supplement 2, pp. S26-S29, 2011.

[86] A. M. C. Barradas, H. Yuan, C. A. van Blitterswijk, and P. Habibovic, "Osteoinductive biomaterials: current knowledge of properties, experimental models and biological mechanisms," European Cells \& Materials, vol. 21, pp. 407-429, 2011.

[87] J. Huang, S. M. Best, W. Bonfield et al., "In vitro assessment of the biological response to nano-sized hydroxyapatite," Journal of Materials Science: Materials in Medicine, vol. 15, no. 4, pp. 441445, 2004.

[88] C. Szpalski, J. Barr, M. Wetterau, P. B. Saadeh, and S. M. Warren, "Cranial bone defects: current and future strategies," Neurosurgical Focus, vol. 29, no. 6, p. E8, 2010.

[89] J. Zhao, Y. Liu, W.-B. Sun, and H. Zhang, "Amorphous calcium phosphate and its application in dentistry," Chemistry Central Journal, vol. 5, article 40, 2011.

[90] K. D. Johnson, K. E. Frierson, T. S. Keller et al., "Porous ceramics as bone graft substitutes in long bone defects: a biomechanical, histological, and radiographic analysis," Journal of Orthopaedic Research, vol. 14, no. 3, pp. 351-369, 1996.

[91] E. B. Nery, K. K. Lee, S. Czajkowski et al., "A Veterans Administration Cooperative Study of biphasic calcium phosphate ceramic in periodontal osseous defects," Journal of Periodontology, vol. 61, no. 12, pp. 737-744, 1990.

[92] S. E. Lobo and T. L. Arinzeh, "Biphasic calcium phosphate ceramics for bone regeneration and tissue engineering applications," Materials, vol. 3, no. 2, pp. 815-826, 2010.
[93] H. R. R. Ramay and M. Zhang, "Biphasic calcium phosphate nanocomposite porous scaffolds for load-bearing bone tissue engineering," Biomaterials, vol. 25, no. 21, pp. 5171-5180, 2004.

[94] V. Petrovic, P. Zivkovic, D. Petrovic, and V. Stefanovic, "Craniofacial bone tissue engineering," Oral Surgery, Oral Medicine, Oral Pathology and Oral Radiology, vol. 114, no. 3, pp. el-e9, 2012.

[95] L. L. Hench, “The story of bioglass," Journal of Materials Science: Materials in Medicine, vol. 17, no. 1, pp. 967-978, 2006.

[96] W. Huang, D. E. Day, K. Kittiratanapiboon, and M. N. Rahaman, "Kinetics and mechanisms of the conversion of silicate (45S5), borate, and borosilicate glasses to hydroxyapatite in dilute phosphate solutions," Journal of Materials Science: Materials in Medicine, vol. 17, no. 7, pp. 583-596, 2006.

[97] W. Huang, M. N. Rahaman, D. E. Day, and Y. Li, "Mechanisms of converting silicate, borate, and borosilicate glasses to hydroxyapatite in dilute phosphate solutions," Physics and Chemistry of Glasses: European Journal of Glass Science and Technology Part $B$, vol. 47, no. 6, pp. 647-658, 2006.

[98] H.-W. Kim, E.-J. Lee, I.-K. Jun, H.-E. Kim, and J. C. Knowles, "Degradation and drug release of phosphate glass/polycaprolactone biological composites for hard-tissue regeneration," Journal of Biomedical Materials Research-Part B Applied Biomaterials, vol. 75, no. 1, pp. 34-41, 2005.

[99] L. L. Hench, "Bioceramics: from concept to clinic," Journal of the American Ceramic Society, vol. 74, no. 7, pp. 1487-1510, 1991.

[100] R. Tevlin, A. McArdle, D. Atashroo et al., "Biomaterials for craniofacial bone engineering," Journal of Dental Research, vol. 93, no. 12, pp. 1187-1195, 2014.

[101] Y. Zhang and C. Wu, "Bioactive inorganic and organic composite materials for bone regeneration and gene delivery," in Advanced Bioactive Inorganic Materials for Bone Regeneration and Drug Delivery, C. Wu, J. Chang, and Y. Xiao, Eds., pp. 178205, CRC Press, Boca Raton, Fla, USA, 2013.

[102] E. Długoń, W. Niemiec, A. Frączek-Szczypta, P. Jeleń, M. Sitarz, and M. Błazewicz, "Spectroscopic studies of electrophoretically deposited hybrid HAp/CNT coatings on titanium," Spectrochimica Acta Part A: Molecular and Biomolecular Spectroscopy, vol. 133, pp. 872-875, 2014.

[103] M. P. Staiger, A. M. Pietak, J. Huadmai, and G. Dias, "Magnesium and its alloys as orthopedic biomaterials: a review," Biomaterials, vol. 27, no. 9, pp. 1728-1734, 2006.

[104] K. Alvarez and H. Nakajima, "Metallic scaffolds for bone regeneration," Materials, vol. 2, no. 3, pp. 790-832, 2009.

[105] N. J. Hallab, J. J. Jacobs, and J. L. Katz, "Application of materials in medicine, biology, and artificial organs: orthopedic applications," in Biomaterials Science: An Introduction to Materials in Medicine, B. D. Ratner, A. S. Hoffman, F. Schoen, and J. E. Lemons, Eds., pp. 526-555, Elsevier Academic Press, New York, NY, USA, 2004.

[106] J.-H. Kim, F. A. Sheikh, H. W. Ju et al., "3D silk fibroin scaffold incorporating titanium dioxide $\left(\mathrm{TiO}_{2}\right)$ nanoparticle (NPs) for tissue engineering," International Journal of Biological Macromolecules, vol. 68, pp. 158-168, 2014.

[107] S. Wu, X. Liu, T. Hu et al., "A biomimetic hierarchical scaffold: natural growth of nanotitanates on three-dimensional microporous Ti-based metals," Nano Letters, vol. 8, no. 11, pp. 38033808, 2008.

[108] H. J. Haugen, M. Monjo, M. Rubert et al., "Porous ceramic titanium dioxide scaffolds promote bone formation in rabbit peri-implant cortical defect model," Acta Biomaterialia, vol. 9, no. 2, pp. 5390-5399, 2013. 
[109] D. Persaud-Sharma and A. McGoron, "Biodegradable magnesium alloys: a review of material development and applications," Journal of Biomimetics, Biomaterials, and Tissue Engineering, vol. 12, no. 1, pp. 25-39, 2012.

[110] B. Heublein, R. Rohde, V. Kaese, M. Niemeyer, W. Hartung, and A. Haverich, "Biocorrosion of magnesium alloys: a new principle in cardiovascular implant technology?” Heart, vol. 89, no. 6, pp. 651-656, 2003.

[111] S. Yoshizawa, A. Brown, A. Barchowsky, and C. Sfeir, "Magnesium ion stimulation of bone marrow stromal cells enhances osteogenic activity, simulating the effect of magnesium alloy degradation," Acta Biomaterialia, vol. 10, no. 6, pp. 2834-2842, 2014.

[112] J. E. Gray and B. Luan, "Protective coatings on magnesium and its alloys-a critical review," Journal of Alloys and Compounds, vol. 336, no. 1-2, pp. 88-113, 2002.

[113] E. Zhang, L. Xu, G. Yu, F. Pan, and K. Yang, "In vivo evaluation of biodegradable magnesium alloy bone implant in the first 6 months implantation," Journal of Biomedical Materials Research, Part A, vol. 90, no. 3, pp. 882-893, 2009.

[114] E. Zhang, L. Xu, and K. Yang, "Formation by ion plating of Ti-coating on pure $\mathrm{Mg}$ for biomedical applications," Scripta Materialia, vol. 53, no. 5, pp. 523-527, 2005.

[115] F. Geng, L. L. Tan, X. X. Jin, J. Y. Yang, and K. Yang, “The preparation, cytocompatibility, and in vitro biodegradation study of pure $\beta$-TCP on magnesium," Journal of Materials Science: Materials in Medicine, vol. 20, no. 5, pp. 1149-1157, 2009.

[116] M. M. Erol, V. Mouriňo, P. Newby et al., "Copper-releasing, boron-containing bioactive glass-based scaffolds coated with alginate for bone tissue engineering," Acta Biomaterialia, vol. 8, no. 2, pp. 792-801, 2012.

[117] M. G. Cascone, N. Barbani, C. Cristallini, P. Giusti, G. Ciardelli, and L. Lazzeri, "Bioartificial polymeric materials based on polysaccharides," Journal of Biomaterials Science, Polymer Edition, vol. 12, no. 3, pp. 267-281, 2001.

[118] I. Manjubala, I. Ponomarev, I. Wilke, and K. D. Jandt, "Growth of osteoblast-like cells on biomimetic apatite-coated chitosan scaffolds," Journal of Biomedical Materials Research Part B: Applied Biomaterials, vol. 84, no. 1, pp. 7-16, 2008.

[119] L. Polo-Corrales, M. Latorre-Esteves, and J. E. Ramirez-Vick, "Scaffold design for bone regeneration," Journal of Nanoscience and Nanotechnology, vol. 14, no. 1, pp. 15-56, 2014.

[120] N. Thuaksuban, T. Nuntanaranont, W. Pattanachot, S. Suttapreyasri, and L. K. Cheung, "Biodegradable polycaprolactonechitosan three-dimensional scaffolds fabricated by melt stretching and multilayer deposition for bone tissue engineering: assessment of the physical properties and cellular response," Biomedical Materials, vol. 6, no. 1, Article ID 015009, 2011.

[121] B. W. Thimm, S. Wüst, S. Hofmann, H. Hagenmüller, and R. Müller, "Initial cell pre-cultivation can maximize ECM mineralization by human mesenchymal stem cells on silk fibroin scaffolds," Acta Biomaterialia, vol. 7, no. 5, pp. 2218-2228, 2011.

[122] L. Moroni, J. R. De Wijn, and C. A. Van Blitterswijk, “3D fiberdeposited scaffolds for tissue engineering: influence of pores geometry and architecture on dynamic mechanical properties," Biomaterials, vol. 27, no. 7, pp. 974-985, 2006.

[123] F. Obregon, C. Vaquette, S. Ivanovski, D. W. Hutmacher, and L. E. Bertassoni, "Three-dimensional bioprinting for regenerative dentistry and craniofacial tissue engineering," Journal of Dental Research, vol. 94, supplement 9, pp. 143S-152S, 2015.
[124] L. Koch, S. Kuhn, H. Sorg et al., "Laser printing of skin cells and human stem cells," Tissue Engineering Part C: Methods, vol. 16, no. 5, pp. 847-854, 2010.

[125] H. N. Chia and B. M. Wu, "Recent advances in 3D printing of biomaterials," Journal of Biological Engineering, vol. 9, article 4, 2015.

[126] W.-Y. Yeong, C.-K. Chua, K.-F. Leong, and M. Chandrasekaran, "Rapid prototyping in tissue engineering: challenges and potential," Trends in Biotechnology, vol. 22, no. 12, pp. 643-652, 2004.

[127] P. X. Ma, "Biomimetic materials for tissue engineering," Advanced Drug Delivery Reviews, vol. 60, no. 2, pp. 184-198, 2008.

[128] C. H. Park, H. F. Rios, A. D. Taut et al., "Image-based, fiber guiding scaffolds: a platform for regenerating tissue interfaces," Tissue Engineering Part C: Methods, vol. 20, no. 7, pp. 533-542, 2014.

[129] M. Figliuzzi, F. G. Mangano, L. Fortunato et al., "Vertical ridge augmentation of the atrophic posterior mandible with custom-made, computer-aided design/computer-aided manufacturing porous hydroxyapatite scaffolds," Journal of Craniofacial Surgery, vol. 24, no. 3, pp. 856-859, 2013.

[130] F. Mangano, A. Macchi, J. A. Shibli et al., "Maxillary ridge augmentation with custom-made CAD/CAM scaffolds. A 1-year prospective study on 10 patients," Journal of Oral Implantology, vol. 40, no. 5, pp. 561-569, 2014.

[131] F. G. Mangano, P. A. Zecca, R. Van Noort et al., "Custom-made computer-Aided-design/computer-Aided-manufacturing biphasic calcium-phosphate scaffold for augmentation of an atrophic mandibular anterior ridge," Case Reports in Dentistry, vol. 2015, Article ID 941265, 11 pages, 2015.

[132] A. Nandakumar, A. Barradas, J. de Boer, L. Moroni, C. van Blitterswijk, and P. Habibovic, "Combining technologies to create bioactive hybrid scaffolds for bone tissue engineering," Biomatter, vol. 3, no. 2, Article ID e23705, 2013.

[133] K. Kim, C. H. Lee, B. K. Kim, and J. J. Mao, "Anatomically shaped tooth and periodontal regeneration by cell homing," Journal of Dental Research, vol. 89, no. 8, pp. 842-847, 2010.

[134] C. H. Lee, J. Hajibandeh, T. Suzuki, A. Fan, P. Shang, and J. J. Mao, "Three-dimensional printed multiphase scaffolds for regeneration of periodontium complex," Tissue Engineering Part A, vol. 20, no. 7-8, pp. 1342-1351, 2014.

[135] T. Akizuki, S. Oda, M. Komaki et al., "Application of periodontal ligament cell sheet for periodontal regeneration: a pilot study in beagle dogs," Journal of Periodontal Research, vol. 40, no. 3, pp. 245-251, 2005.

[136] G. Rasperini, S. P. Pilipchuk, C. L. Flanagan et al., "3D-printed bioresorbable scaffold for periodontal repair," Journal of Dental Research, vol. 94, supplement 9, pp. 153S-157S, 2015.

[137] V. R. Sinha, K. Bansal, R. Kaushik, R. Kumria, and A. Trehan, "Poly- $\varepsilon$-caprolactone microspheres and nanospheres: an overview," International Journal of Pharmaceutics, vol. 278, no. 1, pp. 1-23, 2004.

[138] M. A. Woodruff and D. W. Hutmacher, "The return of a forgotten polymer-polycaprolactone in the 21st century," Progress in Polymer Science, vol. 35, no. 10, pp. 1217-1256, 2010.

[139] R. B. Dixon, N. D. Tricker, and L. P. Garetto, "Bone turnover in elderly canine mandible and tibia," Journal of Dental Research, vol. 76, IADR abstract no. 2579, p. 336, 1997.

[140] E. Díaz, I. Sandonis, and M. B. Valle, "In vitro degradation of poly(caprolactone)/nHA composites," Journal of Nanomaterials, vol. 2014, Article ID 802435, 8 pages, 2014. 
[141] H. F. Rios and W. V. Giannobile, "Preclinical Protocols for Periodontal Regeneration," in Osteology Guidelines for Oral and Maxillofacial Regeneration Preclinical Models for Translational Research, W. V. Giannobile and M. Nevins, Eds., pp. 77-104, Quintessence, Berlin, Germany, 2011.

[142] J. P. Carrel, A. Wiskott, M. Moussa, P. Rieder, S. Scherrer, and S. Durual, "A 3D printed TCP/HA structure as a new osteoconductive scaffold for vertical bone augmentation," Clinical Oral Implants Research, vol. 27, no. 1, pp. 55-62, 2016.

[143] C. Mangano, B. Barboni, L. Valbonetti et al., "In vivo behavior of a custom-made 3D synthetic bone substitute in sinus augmentation procedures in sheep," Journal of Oral Implantology, vol. 41, no. 3, pp. 241-251, 2015.

[144] C. H. Park, K. H. Kim, H. F. Rios, Y. M. Lee, W. V. Giannobile, and Y. J. Seol, "Spatiotemporally controlled microchannels of periodontal mimic scaffolds," Journal of Dental Research, vol. 93, no. 12, pp. 1304-1312, 2014.

[145] U. Hersel, C. Dahmen, and H. Kessler, "RGD modified polymers: biomaterials for stimulated cell adhesion and beyond," Biomaterials, vol. 24, no. 24, pp. 4385-4415, 2003.

[146] D. A. Wahl and J. T. Czernuszka, "Collagen-hydroxyapatite composites for hard tissue repair," European Cells and Materials, vol. 11, pp. 43-56, 2006.

[147] F. Asa’ad, G. Rasperini, G. Pagni, H. F. Rios, and A. B. Giannì, "Pre-augmentation soft tissue expansion: an overview," Clinical Oral Implants Research, vol. 27, no. 5, pp. 505-522, 2016. 


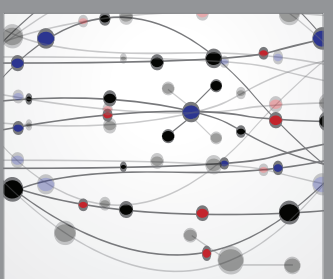

The Scientific World Journal
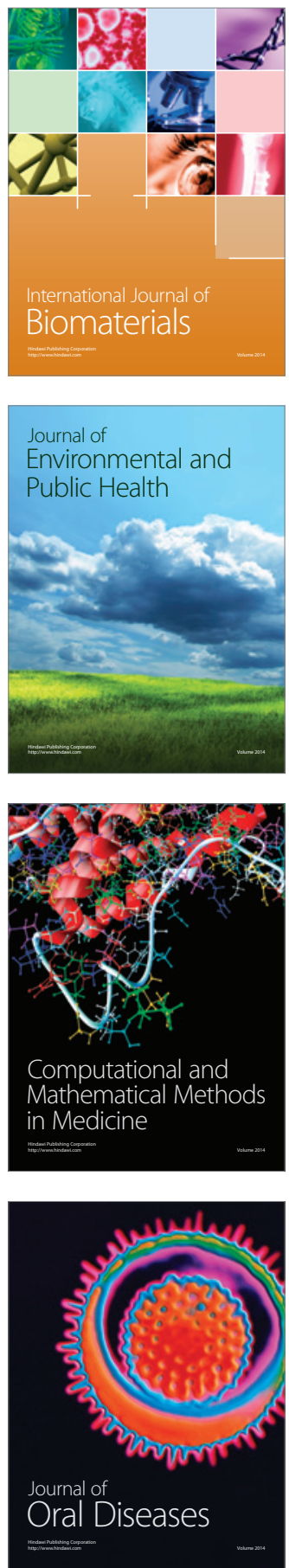
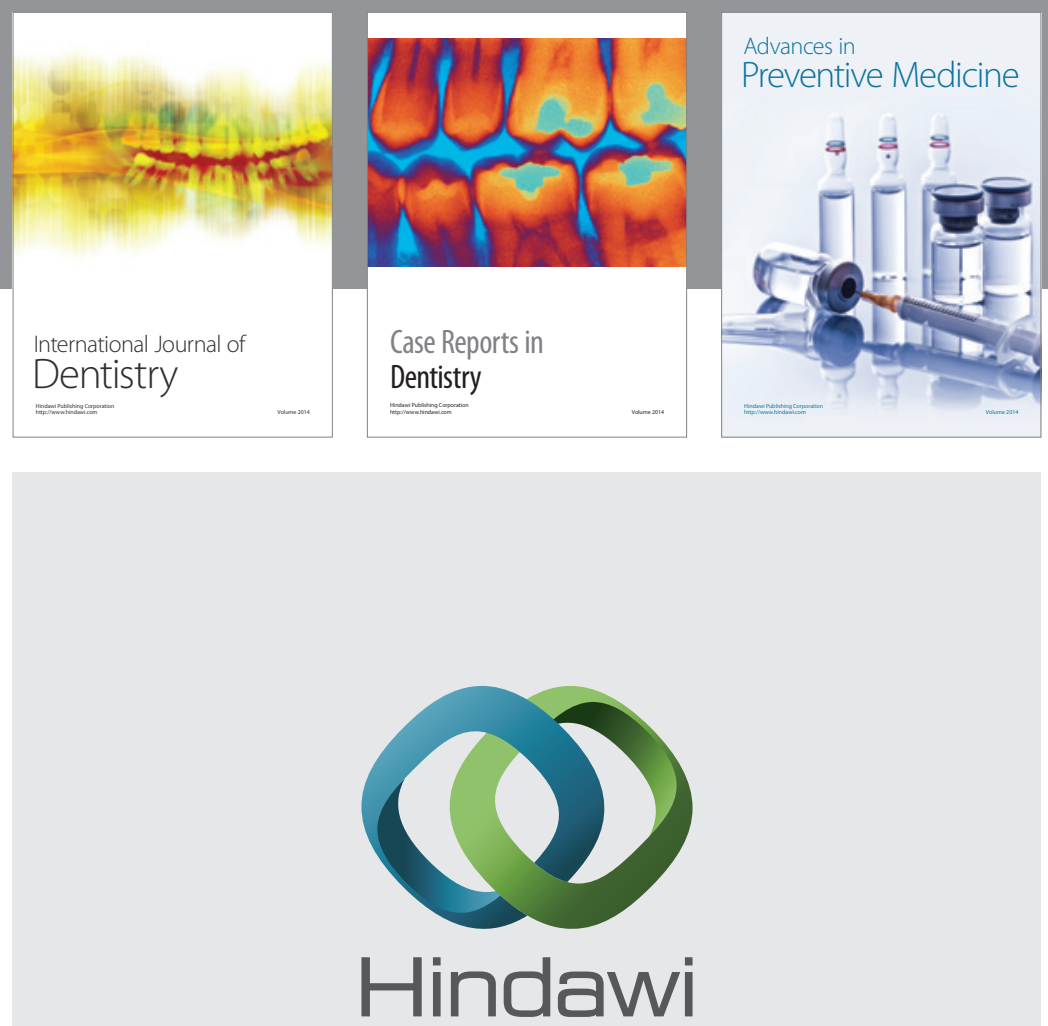

Submit your manuscripts at

http://www.hindawi.com
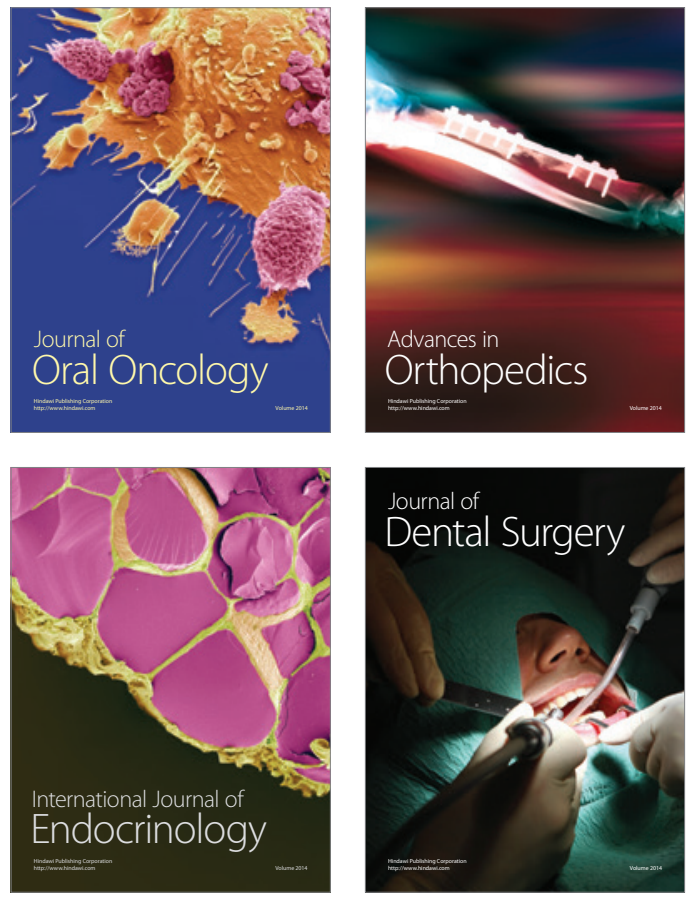
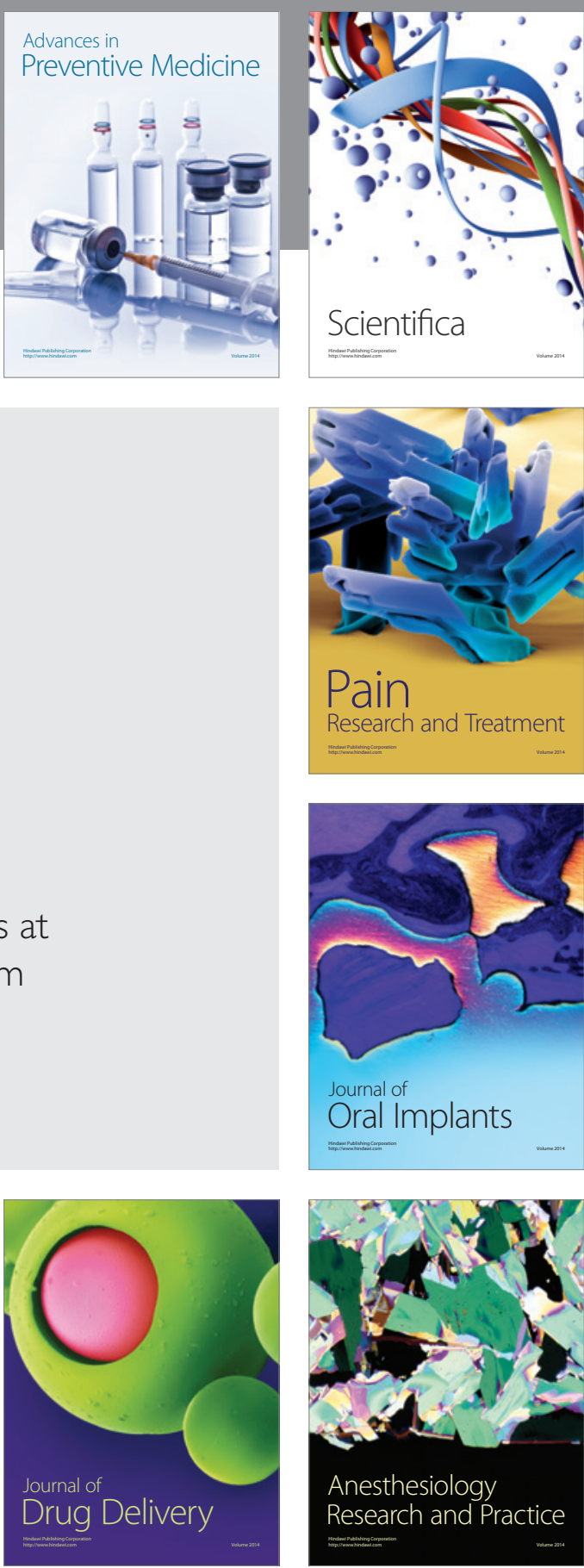

Scientifica
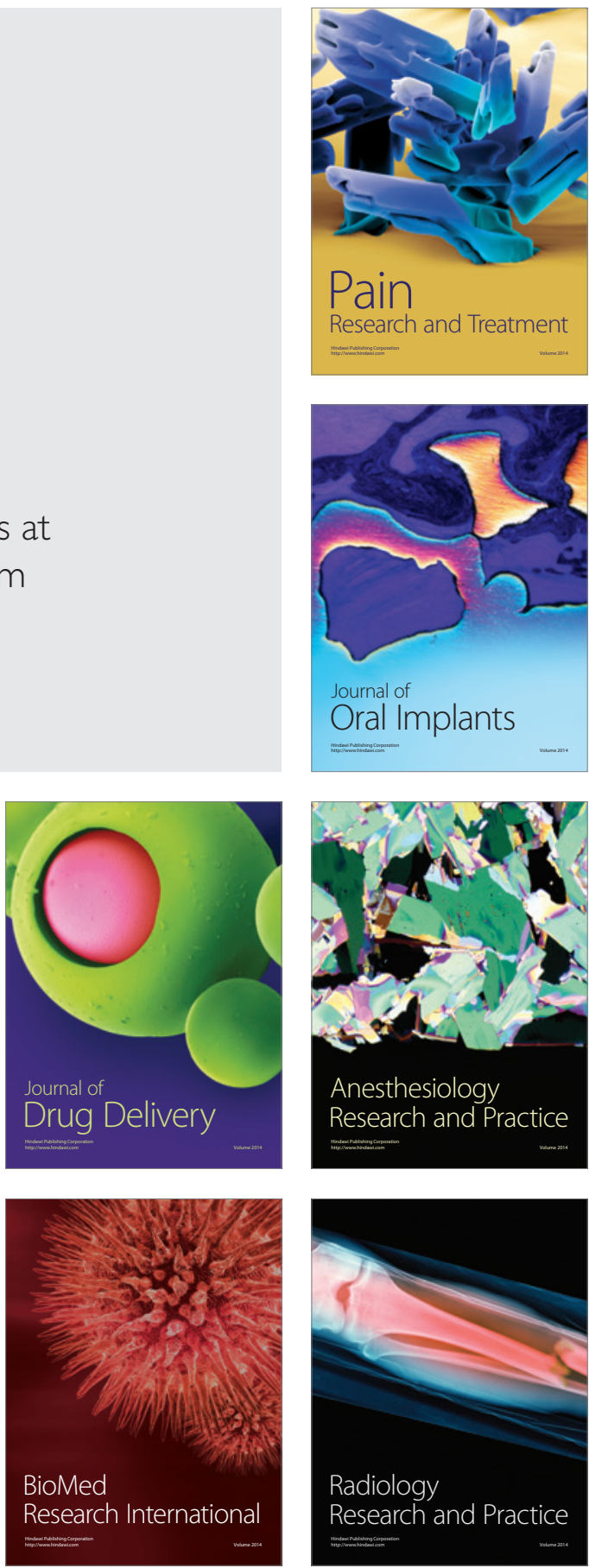